\title{
Parâmetros químicos, bioquímicos e mecânicos de fêmures de frangos de corte submetidos a diferentes balanços eletrolíticos
}

\author{
Elisa Sialino Müller ${ }^{1}$, Anderson de Almeida Barbosa ${ }^{1}$, George Henrique Kling de Moraes ${ }^{1}$, \\ Flávio Medeiros Vieites ${ }^{2}$, Gilson Mendes Araújo²
}

\footnotetext{
1 Departamento de Bioquímica e Biologia Molecular - UFV.

2 Departamento de Zootecnia - UFMT.
}

RESUMO - Objetivou-se avaliar as características ósseas de frangos de corte tratados com diferentes níveis de balanço eletrolítico (BE) na ração. Foram criados 936 pintos de corte Cobb de 1 dia de idade distribuídos em delineamento de blocos ao acaso, com seis tratamentos (BE: -50, 0, 50, 100, 150 e $200 \mathrm{mEq} / \mathrm{kg}$ ), seis repetições e 26 aves por unidade experimental. A ração basal para as duas fases - inicial, 1 a 21 dias, e de crescimento, 22 a 42 dias de idade - foi constituída de milho e farelo de soja, com balanço eletrolítico de $200 \mathrm{mEq} / \mathrm{kg}$. Para obtenção dos outros niveis de BE, a ração basal foi suplementada com cloreto de amônio. Foram avaliados os teores de minerais e proteínas ósseas e os parâmetros geométricos dos fêmures aos 7 , 14, 21 e 42 dias de idade. Aos 7 dias de idade, as aves alimentadas com a ração com BE de $200 \mathrm{mEq} / \mathrm{kg}$ apresentaram o maior teor de magnésio no osso. Os teores de cálcio e fósforo obtidos com BE de $150 \mathrm{mEq} / \mathrm{kg}$ não diferiram dos obtidos com $\mathrm{BE}$ de $200 \mathrm{mEq} / \mathrm{kg}$. A maior relação cálcio:fósforo foi observada nos ossos das aves alimentadas com as rações com BE de 0 e $50 \mathrm{mEq} / \mathrm{kg}$ e o menor teor de cinzas, naquelas cujo BE da ração foi de $200 \mathrm{mEq} / \mathrm{kg}$. O balanço eletrolítico de $200 \mathrm{mEq} / \mathrm{kg}$ de ração promoveu o menor teor de cálcio aos 42 dias de idade, mas, na avaliação da relação cálcio:fósforo, não diferiu do balanço de150 mEq/kg. Os teores de proteínas colagenosas não diferiram aos 21 dias entre os BE de 150 e $200 \mathrm{mEq} / \mathrm{kg}$ de ração. Na avaliação dos parâmetros biomecânicos aos 7 dias, o maior valor de força máxima na flexão foi obtido com o BE de $200 \mathrm{mEq} / \mathrm{kg}$ de ração, demonstrando que na idade de 7 dias, os animais foram mais sensíveis às variações de BE da ração. Aos 14, 21 e 42 dias, podem ser usadas variações mais amplas, de 150 a $200 \mathrm{mEq} / \mathrm{kg}$, nos níveis do balanço eletrolítico, pois não prejudicam as propriedades ósseas de frangos de corte.

Palavras-chave: balanço eletrolítico, fêmur, variação aniônica

\section{Chemical, biochemical and mechanical parameters of femurs of broilers subjected to different electrolyte balance levels}

\begin{abstract}
The objective of this study was to evaluate bone characteristics of broilers treated with different levels EB in the diet. A total of 935 Cobb chicks of 1 day of age were distributed in a randomized blocks design with six treatments (EB: -50, 0, 50, 100, 150 and $200 \mathrm{mEq} / \mathrm{kg}$ ), six replicates and 26 birds per experimental unit. The basal diet for the two phases - starter, from 1 to 21 days and growth, from 22 to 42 days of age - was composed of corn and soybean meal, with electrolytic balance of $200 \mathrm{mEq} / \mathrm{kg}$. For the obtainment of the other EB levels, the basal diet was supplemented with ammonium chloride. Mineral and bone protein contents and geometric parameters of femurs at 7, 14, 21 and 42 days were evaluated. At 7 days of age, birds fed the diet with EB of $200 \mathrm{mEq} / \mathrm{kg}$ presented the highest magnesium content in the bone. The contents of calcium and phosphorus obtained with EB of $150 \mathrm{mEq} / \mathrm{kg}$ did not differ from that achieved with EB of $200 \mathrm{mEq} / \mathrm{kg}$. The greatest calcium:phosphorus ratio was observed in bones of birds fed the diets containing EB of 0 and $50 \mathrm{mEq} / \mathrm{kg}$ and the lowest content of ash was in those consuming the diet whose EB was $200 \mathrm{mEq} / \mathrm{kg}$. The electrolytic balance of $200 \mathrm{mEq} / \mathrm{kg}$ feed promoted the lowest content of calcium at 42 days of age, but at the evaluation of the calcium:phosphorus ratio, it did not differ from the balance of $150 \mathrm{mEq} / \mathrm{kg}$. The content of collagenous proteins did not differ at 21 days between EB of 150 and $200 \mathrm{mEq} / \mathrm{kg}$ feed. At the evaluation of the biomechanical parameters at 7 days, the highest value of maximum bending strength was obtained with the electrolytic balance of $200 \mathrm{mEq} / \mathrm{kg}$ feed, demonstraiting that at 7 days of age the birds were more sensitive to variations of EB of the diet. At 14, 21 and 42 days, wider variations, from 150 to $200 \mathrm{mEq} / \mathrm{kg}$ can be used in the EB levels, for they do not harm the bone properties of broilers.
\end{abstract}

Key Words: anionic variation, electrolyte balance, femur

Recebido em 15/12/2010 e aprovado em 3/2/2012.

Correspondências devem ser enviadas para: esmuller@hotmail.com 


\section{Introdução}

Alguns estudos têm comprovado que o balanço dietético eletrolítico afeta o crescimento e a eficiência alimentar das aves (Simons et al., 1987; Karunajeewa \& Barr, 1988; Karunajeewa et al., 1986). O metabolismo proteico, energético e mineral e a regulação ácido-basica são processos interrelacionados que influenciam o desempenho das aves (Patience, 1990). A manutenção do equilíbrio ácido-base é essencial para os processos fisiológicos e bioquímicos (Sousa et al., 2002), pois pequenas alterações no pH sanguíneo podem afetar processos metabólicos relacionados ao crescimento, à resistência a doenças e à sobrevivência ao estresse por calor (Monteiro et al., 2006). Mongin (1980) enfatizou a importância de se ajustar o conteúdo de minerais da dieta para manter o balanço essencial e o ótimo desempenho, uma vez que, quando o balanço se altera para acidose ou alcalose, as vias metabólicas não funcionam apropriadamente, e as proporções de sódio $(\mathrm{Na})$, cloro $(\mathrm{Cl})$ e potássio $(\mathrm{K})$ na dieta passam a ser consideradas as variáveis mais importantes (Oviedo-Rondon et al., 2000).

Halley et al. (1986) verificaram influência do balanço eletrolítico sobre a incidência de discondroplasia tibial, e isso indica efeito da manipulação no conteúdo de eletrólitos da dieta sobre a capacidade tampão do sangue, o que pode afetar funções do organismo, como a mineralização do osso. Patience (1990) relatou que distúrbios ácido-básicos crônicos afetam o metabolismo ósseo. A acidose metabólica produzida por altos níveis de cloro pode reduzir a formação de $1,25(\mathrm{OH})_{2} \mathrm{D}_{3}$, que é essencial para normal mineralização óssea (Mongin \& Sauveur, 1977). Altas temperaturas também podem afetar o balanço eletrolítico. Frangos de corte criados sob alta temperatura apresentaram reduzida excreção urinária de $\mathrm{Cl}^{-}$e alta excreção de $\mathrm{K}^{+}, \mathrm{Na}^{+}, \mathrm{P}^{-2}, \mathrm{SO}_{4}^{-2}, \mathrm{Mg}^{+2}, \mathrm{Ca}^{+2} \mathrm{e}$ $\mathrm{Mn}^{+2}$ em relação a frangos criados a $24^{\circ} \mathrm{C}$ (Murakami, 2000).

A tíbia tem sido usada como modelo ósseo para avaliação das disfunções metabólicas, porém a sequência na maturação óssea tem desenvolvimento centrípeto, com gradiente de amadurecimento distal (da extremidade) para proximal nos ossos dos membros (Kwakkel et al., 1998). Portanto, é importante a avaliação também do fêmur, pois a velocidade de mineralização e outros aspectos de desenvolvimento deste osso ocorrem mais lentamente que na tíbia, uma vez que está mais próximo ao centro do corpo (Kwakkel et al., 1998). Assim, o fêmur pode ser o principal elo entre o rápido ganho de peso e os problemas de pernas (Barbosa et al., 2010). Assim, objetivou-se avaliar as características ósseas de frangos de corte tratados com diferentes níveis de balanço eletrolítico na ração.

\section{Material e Métodos}

Avaliou-se a composição química, bioquímica e biomecânica dos fêmures de frangos de corte aos 7, 14, 21 e 42 dias de idade. Os fêmures avaliados foram obtidos em experimento realizado no Setor de Avicultura do Centro Federal de Educação Tecnológica de Cuiabá, Mato Grosso. Foram utilizados 936 pintos de corte machos da marca comercial Cobb. As aves foram criadas de 1 até 42 dias de idade em galpão de alvenaria, com pé-direito de 3,0 m de altura. Foram utilizados 36 boxes de 3,54 × 1,13 m $\left(4,0 \mathrm{~m}^{2}\right)$. Utilizou-se delineamento experimental em blocos ao acaso, com seis níveis de balanço eletrolítico (BE), seis repetições (boxes) e 26 aves por unidade experimental. Durante o período experimental, foi adotado programa de luz contínuo, com 24 horas de luz natural + artificial. As temperaturas médias de máxima e de mínima foram 30 e $23^{\circ} \mathrm{C}$, respectivamente, e a umidade relativa do ar média foi $67 \%$.

A ração basal foi constituída de milho e farelo de soja, de forma a atender às recomendações nutricionais descritas por Rostagno (2000) para as fases inicial e de crescimento, compreendendo o período de 1 a 21 e 22 a 42 dias de idade, respectivamente, com BE de $200 \mathrm{mEq} / \mathrm{kg}$ (Tabela 1).

Os animais, com 1 dia de idade e peso médio de $47 \mathrm{~g}$, foram distribuídos uniformemente nos boxes. Cada ração basal foi suplementada com cloreto de amônio $\left(\mathrm{NH}_{4} \mathrm{Cl}\right)$ em substituição ao material inerte, de forma a se obterem seis níveis de balanço eletrolítico (Tabela 2).

Os valores de balanço eletrolítico foram calculados utilizando-se a seguinte fórmula sugerida por Mongin (1981): $\mathrm{BE}=\left(\% \mathrm{Na}^{+} \times 100 / 22,990{ }^{*}\right)+\left(\% \mathrm{~K}^{+} \times 100 / 39,102^{*}\right)$ $-\left(\% \mathrm{Cl}^{-} \times 100 / 35,453^{*}\right) ;\left({ }^{*}\right.$ Equivalente-grama do $\mathrm{Na}^{+}, \mathrm{K}^{+}$ou $\mathrm{Cl}^{-}$, respectivamente).

Aos 7, 14, 21 e 42 dias de idade, uma ave de cada boxe com o peso médio da unidade experimental foi sacrificada por deslocamento cervical. Os fêmures de ambas as pernas foram removidos e limpos de todo o tecido aderente, pesados, medidos quanto ao comprimento, com paquímetro de precisão, e congelados a $-20^{\circ} \mathrm{C}$. As análises laboratoriais foram realizadas no Laboratório de Bioquímica Animal do Departamento de Bioquímica e Biologia Molecular da Universidade Federal de Viçosa.

As análises estatísticas foram realizadas utilizando-se o SAEG (Sistema para Análises Estatísticas e Genéticas, versão 9.1), desenvolvido pela Universidade Federal de Viçosa. Foram feitas análises de variância (5\% de significância) dentro de cada idade. As médias dos tratamentos foram testados pelo teste Dunnet a $5 \%$ de probabilidade. 
Para determinação dos teores de cinzas e minerais, utilizaram-se fragmentos ósseos secos e desengordurados. As amostras foram incineradas em mufla a $550^{\circ} \mathrm{C}$ por 12 horas e pesadas. Os resultados foram expressos em porcentagem de cinzas em relação ao peso do osso seco e desengordurado, de acordo com o método de Thorp \&

Tabela 1 - Composição calculada das rações basais

\begin{tabular}{|c|c|c|}
\hline Ingrediente (\%) & $\begin{array}{l}\text { Fase } \\
\text { inicial }\end{array}$ & $\begin{array}{c}\text { Fase de } \\
\text { crescimento }\end{array}$ \\
\hline Milho & 54,516 & 59,722 \\
\hline Farelo de soja & 36,179 & 30,524 \\
\hline Óleo de soja & 3,724 & 4,291 \\
\hline Calcário & 0,977 & 0,927 \\
\hline Fosfato bicálcico & 1,825 & 1,623 \\
\hline DL-metionina (99\%) & 0,230 & 0,209 \\
\hline L-lisina $\mathrm{HCl}(98 \%)$ & 0,153 & 0,198 \\
\hline Sal comum & 0,456 & 0,462 \\
\hline Carbonato de potássio & - & 0,104 \\
\hline Cloreto de amônio & 0,062 & - \\
\hline Cloreto colina (60\%) & 0,080 & 0,080 \\
\hline Mistura vitamínico ${ }^{1}$ & 0,100 & 0,100 \\
\hline Mistura mineral $^{2}$ & 0,050 & 0,050 \\
\hline Virginamicina $^{3}$ & 0,050 & 0,050 \\
\hline Anticoccidiano 4 & 0,050 & 0,050 \\
\hline Antioxidante $^{5}$ & 0,010 & 0,010 \\
\hline Areia lavada (inerte) & 1,600 & 1,600 \\
\hline Total & 100,00 & 100,00 \\
\hline \multicolumn{3}{|l|}{ Exigências nutricionais (\%) } \\
\hline Energia metabolizável (kcal/kg) & 3.000 & 3.100 \\
\hline Proteína bruta (\%) & 21,40 & 19,30 \\
\hline Cálcio (\%) & 0,960 & 0,874 \\
\hline Fósforo disponível (\%) & 0,450 & 0,406 \\
\hline Sódio (\%) & 0,222 & 0,222 \\
\hline Potássio (\%) & 0,829 & 0,799 \\
\hline Cloro (\%) & 0,386 & 0,359 \\
\hline Arginina digestível (\%) & 1,336 & 1,177 \\
\hline Glicina + serina $(\%)$ & 2,024 & 1,812 \\
\hline Metionina + cistina digestível (\%) & 0,807 & 0,741 \\
\hline Lisina digestível (\%) & 1,143 & 1,045 \\
\hline Treonina digestível (\%) & 0,717 & 0,643 \\
\hline Triptofano digestível (\%) & 0,242 & 0,211 \\
\hline Balanço eletrolítico (mEq/kg) & 200 & 200 \\
\hline \multicolumn{3}{|c|}{$\begin{array}{l}{ }^{1} \text { Suplementação de vitaminas, minerais e aditivos/kg do produto; vit. A - } \\
10.000 .000 \text { UI; vit. D3 - } 2.000 .000 \text { UI; vit. E - } 30.000 \text { UI; vit. B1 - 2,0 g; vit. } \\
\text { B6 - 4,0 g; ácido pantotênico - } 12,0 \text { g; biotina - } 0,10 \text { g; vit. K3 - 3,0 g; ácido } \\
\text { fólico - 1,0 g; ácido nicotínico - 50,0 g; vit. B12 - } 15.000 \text { mcg; selênio - 0,25 g; } \\
\text { veículo q.s.p. - } 1.000 \text { g. } \\
2 \text { Roligomix (Roche) - Níveis de garantia por quilo de produto: manganês - } 16,0 \text { g; } \\
\text { ferro - } 100,0 \text { g; zinco - } 100,0 \text { g; cobre - } 20,0 \text { g; cobalto - 2,0 g; iodo - 2,0 g; } \\
\text { veículo q.s.p. - } 1.000 \text { g. } \\
{ }^{3} \text { Stafac }{ }^{\circledR}-50 \% \text {. } \\
{ }^{4} \text { Coxistac }{ }^{\circledR} \text { (salinomicina) - } 12 \% \text {. } \\
5 \text { Butil-hidroxi-tolueno. }\end{array}$} \\
\hline
\end{tabular}

Waddington (1997). Para determinação por espectrometria de absorção atômica dos teores de $\mathrm{Na}, \mathrm{K}, \mathrm{Ca}, \mathrm{P}$ e Mg nas cinzas, $10 \mathrm{~mL}$ de ácido clorídrico $(6 \mathrm{M})$ foram adicionados às cinzas com a finalidade de descomplexar os cristais de hidroxiapatita, liberando os minerais. Essas amostras foram colocadas sobre uma placa de aquecimento e a solução foi evaporada em capela de exaustão até secar completamente. O precipitado foi dissolvido por adição de água destilada e deionizada e na solução filtrada o volume completado para $30 \mathrm{~mL}$ para a idade de 7 e 14 dias de idade e para $50 \mathrm{~mL}$ para as idades de 21 e 42 dias de idade (Thorp \& Waddington, 1997).

Os fêmures utilizados para o teste de flexão foram cortados longitudinalmente, removendo-se a medula óssea com jatos de água destilada e deionizada. A seguir, foram desengordurados com éter de petróleo, em aparelho de Soxhlet, por 12 horas, e utilizados para determinação das concentrações das proteínas não-colagenosas e colagenosas. Para tanto, os fêmures foram desmineralizados extensivamente com solução de EDTA 0,5M e pH 8,2, de acordo com o método proposto por Hauschka \& Gallop (1977) para extração das Gla-proteínas ósseas ou proteínas nãocolagenosas. O fim da extração foi confirmado com o ácido oxálico. Após a extração, os volumes foram ajustados para $5 \mathrm{~mL}$ para a idade de 7 dias, $14 \mathrm{~mL}$ para 14 dias, $30 \mathrm{~mL}$ para 21 dias e $80 \mathrm{~mL}$ para 42 dias. As proteínas não-colagenosas foram quantificadas na solução de EDTA pelo método de Bradford (1976) utilizando-se albumina sérica bovina como padrão.

Depois de desengordurados e desmineralizados, os ossos foram lavados com água destilada e deionizada para extração do EDTA e, então, usados para determinação do teor de proteínas colagenosas, utilizando-se o método Kjeldahl segundo Silva \& Queiroz (2006). O teor de proteínas colagenosas (PC) foi obtido multiplicando-se o teor de nitrogênio pelo fator 6,25.

A avaliação dos aspectos biomecânicos dos fêmures foi realizado de acordo com Barbosa et al. (2010). Os fêmures esquerdos foram descongelados até atingir a temperatura ambiente e submetidos a ensaio de flexão segundo norma ANSI/ASAE S459-98 (1992) em máquina universal de ensaios mecânicos EMIC.

Tabela 2 - Tratamentos constituídos pelas rações experimentais (inicial e de crescimento) suplementadas com $\mathrm{NH}_{4} \mathrm{Cl}$

\begin{tabular}{|c|c|c|c|c|}
\hline Balanço eletrolítico (mEq/kg) & Ração basal (kg) & Inerte $(\%)$ & $\mathrm{NH}_{4} \mathrm{Cl}(\%)$ & Total (\%) \\
\hline-50 & 98,4 & 0,255 & 1,345 & 100 \\
\hline 0 & 98,4 & 0,524 & 1,076 & 100 \\
\hline 50 & 98,4 & 0,793 & 0,807 & 100 \\
\hline 100 & 98,4 & 1,062 & 0,538 & 100 \\
\hline 150 & 98,4 & 1,331 & 0,269 & 100 \\
\hline 200 & 98,4 & 1,600 & - & 100 \\
\hline
\end{tabular}

$\mathrm{NH}_{4} \mathrm{Cl}$ - peso molecular (U.M.A.) = 53,45; pureza 99,5\%. 


\section{Resultados e Discussão}

Os balanços eletrolíticos interferiram nas porcentagens de cinzas, na relação cálcio:fósforo e nos teores de cálcio, fósforo e magnésio (Tabela 3) aos 7 dias. Somente o nível de $150 \mathrm{mEq} / \mathrm{kg}$ não diferiu do controle ( $200 \mathrm{mEq} / \mathrm{kg}$ ) quanto aos teores de cálcio $(\mathrm{P}>0,05)$ e fósforo. Todos os teores de magnésio obtidos com os níveis de balanço eletrolítico testados foram inferiores $(\mathrm{P}<0,05)$ ao observado no nível controle. A relação cálcio:fósforo obtida com os balanços eletrolíticos de 0 e $50 \mathrm{mEq} / \mathrm{kg}$ diferiu, com valores superiores $(\mathrm{P}<0,05)$ ao observado no grupo controle. Finalmente, o teor de cinzas observado nas aves do grupo controle foi menor $(\mathrm{P}<0,05)$ que em todos os demais grupos.

Para a idade de 14 dias, os balanços eletrolíticos da ração interferiram nas porcentagens de sódio nas cinzas, sendo apenas o grupo contendo $100 \mathrm{mEq} / \mathrm{kg}$ igual ao controle $(\mathrm{P}>0,05)$.

A variação dos níveis de balanço eletrolítico na dieta não interferiu $(\mathrm{P}>0,05)$ nos parâmetros químicos dos fêmures dos frangos na idade de 21 dias, fato comprovado pelo teste
Dunnett a 5\% de probabilidade. Todavia, Vieites et al. (2004) verificaram que o melhor balanço eletrolítico para a deposição de cálcio em tíbias foi de $132 \mathrm{mEq} / \mathrm{kg}$ para frangos de corte aos 21 dias de idade.

Aos 42 dias de idade, a variação do balanço eletrolítico interferiu na relação cálcio:fósforo e nos teores do cálcio dos fêmures. O grupo controle apresentou o menor teor de cálcio nas cinzas $(\mathrm{P}<0,05)$. A relação cálcio:fósforo observada com o balanço eletrolítico de $150 \mathrm{mEq} / \mathrm{kg}$ foi igual à obtida com o nível controle ( $\mathrm{P}>0,05)$.

Neste trabalho, para a variação aniônica aos 7 dias de idade as porcentagens de cálcio e fósforo foram menores que o controle a partir do nível de $100 \mathrm{mEq} / \mathrm{kg}$, em todos os níveis de cloro. O excesso de cloro na dieta leva a uma acidose metabólica que pode reduzir a capacidade de síntese de $1,25(\mathrm{OH})_{2} \mathrm{D} 3$, que é essencial para o estímulo da absorção do cálcio no intestino (Waldenstedt, 2006). Contrariamente, Araújo (2009) encontrou maior teor de cálcio nas cinzas quando utilizou balanço eletrolítico de $-50 \mathrm{mEq} / \mathrm{kg}$ aos 7 dias de idade. No entanto, aos 42 dias de idade neste trabalho, observou-se o mesmo que Araújo (2009), com

Tabela 3 - Aspectos químicos dos fêmures de frangos de corte alimentados com rações de diferentes níveis de balanço eletrolítico

\begin{tabular}{|c|c|c|c|c|c|c|c|c|}
\hline \multirow[b]{2}{*}{ Balanço } & \multirow[b]{2}{*}{ eletrolítico (mEq/kg) } & \multicolumn{6}{|c|}{ Minerais no osso (\%) } & \multirow[b]{2}{*}{$\%$ cinzas } \\
\hline & & Cálcio & Fósforo & Magnésio & Sódio & Potássio & Relação cálcio:fósforo & \\
\hline & & & & & 7 dias & & & \\
\hline & -50 & $12,98^{*}$ & $8,16^{*}$ & $0,41^{*}$ & $1,26^{\mathrm{ns}}$ & $1,87^{\mathrm{ns}}$ & $1,59^{*}$ & $47,01^{*}$ \\
\hline & 0 & $13,80^{*}$ & $8,28^{*}$ & $0,42^{*}$ & $1,22^{\mathrm{ns}}$ & $1,72^{\mathrm{ns}}$ & $1,67^{*}$ & $49,79^{*}$ \\
\hline & 50 & $12,95^{*}$ & $7,89^{*}$ & $0,39^{*}$ & $1,01^{\mathrm{ns}}$ & $1,38^{\mathrm{ns}}$ & $1,64^{*}$ & $52,16^{*}$ \\
\hline & 100 & $13,84^{*}$ & $8,78^{*}$ & $0,43^{*}$ & $1,28^{\mathrm{ns}}$ & $2,00^{\mathrm{ns}}$ & $1,58^{*}$ & $42,51^{*}$ \\
\hline & 150 & $15,57^{\mathrm{ns}}$ & $9,56^{\mathrm{ns}}$ & $0,47^{*}$ & $1,11^{\mathrm{ns}}$ & $1,63^{\mathrm{ns}}$ & $1,63^{\mathrm{ns}}$ & $47,11^{*}$ \\
\hline \multirow{2}{*}{\multicolumn{2}{|c|}{$200^{* *}$}} & 17,44 & 10,71 & 0,56 & 1,25 & 2,28 & 1,63 & 39,25 \\
\hline & & & & & 14 dias & & & \\
\hline & -50 & $14,80^{\mathrm{ns}}$ & $8,65^{\mathrm{ns}}$ & $0,44^{\mathrm{ns}}$ & $0,75^{*}$ & $1,05^{\mathrm{ns}}$ & $1,71^{\mathrm{ns}}$ & $52,45^{\mathrm{ns}}$ \\
\hline & 0 & $13,92^{\mathrm{ns}}$ & $8,06^{\mathrm{ns}}$ & $0,44^{\mathrm{ns}}$ & $0,73^{*}$ & $0,96^{\mathrm{ns}}$ & $1,72^{\mathrm{ns}}$ & $53,45^{\mathrm{ns}}$ \\
\hline & 50 & $13,18^{\mathrm{ns}}$ & $7,78^{\mathrm{ns}}$ & $0,41^{\mathrm{ns}}$ & $0,67^{*}$ & $0,90^{\mathrm{ns}}$ & $1,69^{\mathrm{ns}}$ & $54,48^{\mathrm{ns}}$ \\
\hline & 100 & $12,62^{\mathrm{ns}}$ & $7,58^{\mathrm{ns}}$ & $0,40^{\mathrm{ns}}$ & $0,63^{\mathrm{ns}}$ & $0,82^{\mathrm{ns}}$ & $1,67^{\mathrm{ns}}$ & $55,31^{\mathrm{ns}}$ \\
\hline & 150 & $14,02^{\mathrm{ns}}$ & $8,32^{\mathrm{ns}}$ & $0,43^{\mathrm{ns}}$ & $0,68^{*}$ & $0,79^{\mathrm{ns}}$ & $1,68^{\mathrm{ns}}$ & $52,82^{n s}$ \\
\hline \multirow{2}{*}{\multicolumn{2}{|c|}{$200^{* *}$}} & 14,08 & 8,38 & 0,41 & 0,63 & 0,85 & 1,68 & 55,29 \\
\hline & & & & & 21 dias & & & \\
\hline & -50 & $20,25^{\mathrm{ns}}$ & $12,48^{\mathrm{ns}}$ & $0,67^{\mathrm{ns}}$ & $1,18^{\mathrm{ns}}$ & $0,56^{\mathrm{ns}}$ & $1,62^{\mathrm{ns}}$ & $53,71^{\mathrm{ns}}$ \\
\hline & 0 & $20,92^{n s}$ & $12,31^{\mathrm{ns}}$ & $0,64^{\mathrm{ns}}$ & $1,22^{\mathrm{ns}}$ & $0,61^{\mathrm{ns}}$ & $1,70^{\text {ns }}$ & $53,64^{\mathrm{ns}}$ \\
\hline & 50 & $20,03^{\mathrm{ns}}$ & $11,64^{\mathrm{ns}}$ & $0,62^{\mathrm{ns}}$ & $1,14^{\mathrm{ns}}$ & $0,61^{\mathrm{ns}}$ & $1,72^{\mathrm{ns}}$ & $55,24^{\mathrm{ns}}$ \\
\hline & 100 & $19,73^{n s}$ & $11,92^{\mathrm{ns}}$ & $0,58^{\mathrm{ns}}$ & $1,24^{\mathrm{ns}}$ & $0,67^{\text {ns }}$ & $1,66^{\mathrm{ns}}$ & $54,27^{\mathrm{ns}}$ \\
\hline & 150 & $20,55^{\mathrm{ns}}$ & $12,42^{\mathrm{ns}}$ & $0,62^{\mathrm{ns}}$ & $1,25^{\mathrm{ns}}$ & $0,65^{\mathrm{ns}}$ & $1,66^{\mathrm{ns}}$ & $56,37^{\mathrm{ns}}$ \\
\hline \multirow{2}{*}{\multicolumn{2}{|c|}{$200^{* *}$}} & 16,95 & 9,91 & 0,59 & 1,16 & 0,58 & 1,61 & 55,90 \\
\hline & & & & & 42 dias & & & \\
\hline & -50 & $25,69^{*}$ & $13,35^{\mathrm{ns}}$ & $0,71^{\mathrm{ns}}$ & $0,94^{\mathrm{ns}}$ & $0,68^{\mathrm{ns}}$ & $1,93^{*}$ & $57,94^{\mathrm{ns}}$ \\
\hline & 0 & $28,82^{*}$ & $14,17^{\mathrm{ns}}$ & $0,79^{\mathrm{ns}}$ & $1,00^{\mathrm{ns}}$ & $0,60^{\mathrm{ns}}$ & $2,03^{*}$ & $57,00^{\mathrm{ns}}$ \\
\hline & 50 & $27,70^{*}$ & $13,79^{\mathrm{ns}}$ & $0,78^{\mathrm{ns}}$ & $1,00^{\mathrm{ns}}$ & $0,68^{\mathrm{ns}}$ & $2,01^{*}$ & $56,96^{\mathrm{ns}}$ \\
\hline & 100 & $29,10^{*}$ & $14,87^{\mathrm{ns}}$ & $0,83^{\mathrm{ns}}$ & $0,98^{\mathrm{ns}}$ & $0,72^{\mathrm{ns}}$ & $1,96^{*}$ & $57,72^{\mathrm{ns}}$ \\
\hline & 150 & $18,65^{*}$ & $11,48^{\mathrm{ns}}$ & $0,60^{\mathrm{ns}}$ & $0,89^{\mathrm{ns}}$ & $0,68^{\mathrm{ns}}$ & $1,63^{\mathrm{ns}}$ & $57,76^{\mathrm{ns}}$ \\
\hline & $200^{* *}$ & 16,64 & 10,14 & 0,58 & 0,86 & 0,67 & 1,54 & 55,80 \\
\hline
\end{tabular}

ns Não-significativo a $5 \%$ de probabilidade pelo teste Dunnett.

* Significativo a $5 \%$ de probabilidade pelo teste Dunnett.

** Controle. 
redução dos níveis de cálcio nas cinzas com o balanço de $200 \mathrm{mEq} / \mathrm{kg}$ quando houve havia menores quantidades equimolares de cloro na dieta.

O aumento da quantidade de cloro da dieta aumenta as anormalidades das cartilagens, especialmente quando o conteúdo de sódio e o potássio estão baixos na dieta. Dietas suplementadas com $\mathrm{NH}_{4} \mathrm{Cl} \mathrm{e} \mathrm{NaHCO}_{3}$ aumentaram a excreção de cálcio pelos rins, isto porque o osso funciona como um sistema tamponante para o controle ácido-base dos fluidos corporais. Dietas ácidas induzem a liberação de cátions (incluindo o cálcio) do osso para o sangue para corrigir seu pH; e para cada mol de cálcio depositado, 9 moles de ácidos são liberados (Patience 1990). A acidose metabólica estimula primeiro a dissolução mineral e depois a reabsorção óssea mediada por células, devido à maior excreção de cálcio pelos rins (Oliveira et al., 2010). Neste trabalho, aos 7 dias de idade, houve este efeito, pois a porcentagem de cálcio foi maior quando se diminuiu o teor de cloro na dieta. Então, é possível inferir que, pelo menos nesta idade, com níveis de balanço eletrolítico mais baixos, o osso tenha fornecido cálcio para o sangue, culminando em menor porcentagem de cálcio ósseo.

Embora as relações cálcio:fósforo tenham sido afetadas significativamente nas idades de 7 e 42 dias para os valores de balanço eletrolítico de 150 e $200 \mathrm{mEq} / \mathrm{kg}$, estes valores foram mantidos próximos aos preconizados por Williams et al. (2000) como relação ideal (1,67:1), embora Field (2000) tenha considerado que a relação ideal seja em torno de 2:1. Entretanto, Williams et al. (2000) não observaram diferenças nas propriedades mecânicas dos ossos quando as relações cálcio:fósforo variaram de 1,82:1 até 3,89:1.

Distúrbios severos no balanço ácido-base ou no suprimento de certos eletrólitos são refletidos na composição de sais dos ossos. Uma quantidade de sódio e potássio pode ser mobilizada do esqueleto sob circunstâncias apropriadas sem dissolução geral da matriz do cristal (Brown \& Jaffe, 2000). A composição de sais dos ossos não é fixa, mas reflete o estado de equilíbrio químico do corpo. Bergstrom \& Wallace (1954) já haviam indicado uma troca desproporcional entre o sódio e o cálcio no osso. Portanto, as relações cálcio:fósforo só serão alteradas durante um período de acidose prolongada no qual o sódio e o potássio ósseo que estão prontamente disponíveis para troca com prótons $\left(\mathrm{H}^{+}\right)$estiverem esgotados, sendo necessária a dissolução da matriz óssea e com consequente liberação desses minerais do osso. Neste trabalho, a quantidade em porcentagem de sódio nos fêmures aos 14 dias foi significativamente menor no balanço de $200 \mathrm{mEq} / \mathrm{kg}$. Entretanto, esta variação pode não estar associada aos fatores previamente descritos, visto que as quantidades de sódio na dieta não foram alteradas e para $200 \mathrm{mEq} / \mathrm{kg}$ os níveis de cloro foram os mais baixos entre os tratamentos. Ossos de animais mais jovens possuem maiores quantidades de água e estão em fase de constante remodelamento, o que proporciona maior possibilidade de liberação de íons para servirem ao sistema tamponante sistêmico (Green \& Kleeman, 1991). Nas outras idades, não houve influência do balanço eletrolítico sobre os níveis de sódio e potássio.

Houve diferenças significativas nas concentrações de magnésio apenas para $200 \mathrm{mEq} / \mathrm{kg}$ na idade de 7 dias, e isso evidencia que o balanço de $200 \mathrm{mEq} / \mathrm{kg}$ foi o que proporcionou maior deposição óssea de magnésio nesta idade. O magnésio ósseo será mobilizado principalmente durante uma deficiência deste elemento e não em resposta às mudanças de $\mathrm{pH}$; este fato foi comprovado neste trabalho. O magnésio pode ser incorporado no lugar do cálcio no osso em quantidades que dependem de sua concentração sanguínea. Do magnésio corporal 60\% estão presentes nos ossos (Waldenstedt, 2006). Diferentemente do potássio e do cloro, que são facilmente e totalmente trocados no osso, o magnésio e o sódio podem penetrar na camada superficial da matriz óssea e são menos disponíveis para trocas nesta fase. Portanto, a resposta às alterações catiônicas provenientes de deficiências nutricionais ou acidose metabólica difere em termos de respostas para o sódio e potássio versus magnésio.

As deficiências de cálcio e fósforo dietético podem ocasionar redução do conteúdo de cinzas (Field, 2000). Neste trabalho as porcentagens de cinzas encontradas estão de acordo com o observado por Thorp \& Waddington (1997), que obtiveram $55,6 \%$ em frangos de corte com 35 dias de idade. Leterrier \& Nys (1992) também observaram aumento das porcentagens de cinzas em tíbias com o aumento da idade, variando de $26 \%$ ao primeiro dia de vida até o máximo de 39\% aos 22 dias de idade. Contrariamente ao que se esperava, o balanço eletrolítico de $200 \mathrm{mEq} / \mathrm{kg}$ aos 7 dias de idade apresentou valores significativamente menores de cinzas. Esse resultado difere do observado por Araújo (2009), que encontrou o menor valor para cinzas no balanço eletrolítico de $-50 \mathrm{mEq} / \mathrm{kg}$ e relatou que o teor de cinzas aumentou à medida que foi reduzida a inclusão de $\mathrm{NH}_{4} \mathrm{Cl}$ nas rações, comprovando efeito negativo da acidificação da dieta sob a mineralização óssea. Moghaddam et al. (2005) não notaram diferenças nos teores de cinza e cálcio quando variaram o balanço eletrolítico em frangas de 7 a 35 dias de idade.

Para os teores de proteínas colagenosas e nãocolagenosas, os balanços eletrolíticos da ração interferiram significativamente apenas na idade de 21 dias para proteína 
colagenosa (Tabela 4), sendo que apenas o nível de $150 \mathrm{mEq} / \mathrm{kg}$ não diferiu do controle $(\mathrm{P}<0,05)$.

Anormalidades do tecido ósseo podem estar associadas aos altos teores de proteínas não-colagenosas dos ossos das pernas de frangos de corte. O aumento de Gla-proteínas implica tanto na mineralização óssea quanto na estimulação à liberação de cálcio do osso (Moraes et al., 2010). Como neste trabalho não houve diferença significativa nos teores de proteína não-colagenosa, pode-se afirmar que o balanço eletrolítico de -50 a $200 \mathrm{mEq} / \mathrm{kg}$ não gerou desequilíbrio metabólico a ponto de interferir no parâmetro proteína não-colagenosa nas condições avaliadas. Diferente deste trabalho, Oliveira et al. (2006) observaram que o balanço eletrolítico de $153 \mathrm{mEq} / \mathrm{kg}$ possibilitou maior deposição de proteína não-colagenosa nos ossos longos das aves aos 21 dias de idade.

As propriedades ósseas são proporcionadas pelos seus constituintes principais, água, minerais e matriz orgânica, principalmente o colágeno tipo I. Todavia, as relações das quantidades entre eles interferem em algumas características biomecânicas relacionadas às propriedades de suportar carga (Currey, 2003). O colágeno é o principal componente proteico do osso e corresponde a $90 \%$ de seu conteúdo; sua função é fornecer tenacidade à estrutura óssea para que o osso sofra flexão sem se quebrar. Portanto, o colágeno permite ao osso suportar maior carga, independentemente de sua rigidez, que é proporcionada pelos cristais de apatita. Neste trabalho só foi observada diferença significativa aos 21 dias para os balanços de 150 e $200 \mathrm{mEq} / \mathrm{kg}$ para proteínas colagenosas, contrariamente ao que se esperava, pois, nestes níveis as proporções de minerais dos ossos deveriam ser maiores; porém, aos 21 dias, o balanço eletrolítico adequado pode interferir no crescimento do animal, fazendo com que os ossos também se desenvolvam mais, com maior velocidade no ciclo de remodelação óssea, impedido a deposição de uma matriz óssea mais madura (Crespo et al., 2002). Outro aspecto que pôde ter contribuído para não observação de diferenças significativas para proteínas colagenosas nos diferentes níveis de balanço eletrolítico é que regiões diferentes do mesmo osso possuem níveis de mineralização diferentes. Regiões onde existe maior quantidade de ossos esponjosos são menos mineralizadas e podem expressar melhor certas diferenças. Como no presente trabalho as proteínas colagenosas foram avaliadas dos ossos inteiros, outras regiões menos sensíveis, como a região mediana dos ossos, podem ter mascarado as diferenças da região de crescimento ósseo (Muamba \& Gerver, 1989).

Os parâmetros biomecânicos são indicativos da verdadeira qualidade óssea e são determinados pela densidade (Barreiro et al., 2011) e força máxima na flexão (Reis et al., 2011). Aos 7 dias de idade, as dietas contendo diferentes balanços eletrolíticos interferiram apenas nos valores da força máxima na flexão (Tabela 5). O grupo controle (BE de $200 \mathrm{mEq} / \mathrm{kg}$ ) apresentou o menor valor em relação aos tratamentos $(\mathrm{P}<0,05)$.

O parâmetro SpE não apresentou diferenças significativas $(\mathrm{P}>0,05)$ para nenhuma idade, diferindo do observado por Araújo (2009), que encontrou maior resultado para o balanço eletrolítico de $50 \mathrm{mEq} / \mathrm{kg}$. Esse autor relatou ainda que, ao contrário do esperado, houve aumento da carga máxima suportada pelos ossos à medida que as dietas foram acidificadas.

O osso funciona como um sistema tamponante para o controle ácido-base dos fluidos corporais. Dietas ácidas induzem a liberação de cátions (incluindo o cálcio) do osso para o sangue para corrigir seu pH (Oliveira et al., 2010). A acidose metabólica estimula primeiro a dissolução mineral e depois a reabsorção óssea mediada por células, devido à maior excreção de cálcio pelos rins (Riond, 2001; Oliveira et al., 2010). Essa perda de cálcio resultaria em menor mineralização óssea, podendo afetar a qualidade mecânica dos ossos no animal. Um fator importante é que a quantidade de cálcio no osso tem sido associada à fragilidade óssea. Thorp \& Waddington (1997) observaram que ossos com valores inferiores de cálcio fraturavam mais durante o processamento. Crespo et al. (2002) também encontraram

Tabela 4 - Teores de proteínas colagenosas e não-colagenosas dos fêmures de frangos de corte alimentados com diferentes níveis de balanço eletrolítico

\begin{tabular}{|c|c|c|c|c|c|c|c|c|}
\hline \multirow[t]{2}{*}{ Balanço eletrolítico (mE/kg) } & \multicolumn{4}{|c|}{ \% proteína colagenosa } & \multicolumn{4}{|c|}{ \% proteína não-colagenosa } \\
\hline & 7 dias & 14 dias & 21 dias & 42 dias & 7 dias & 14 dias & 21 dias & 42 dias \\
\hline-50 & $59,16^{\mathrm{ns}}$ & $51,14^{\mathrm{ns}}$ & $40,15^{*}$ & $46,67^{\mathrm{ns}}$ & $0,85^{\mathrm{ns}}$ & $0,48^{\mathrm{ns}}$ & $0,46^{\mathrm{ns}}$ & $0,39^{\text {ns }}$ \\
\hline 0 & $55,54^{\mathrm{ns}}$ & $53,37^{\mathrm{ns}}$ & $43,65^{*}$ & $46,97^{\mathrm{ns}}$ & $0,93^{\mathrm{ns}}$ & $0,36^{\mathrm{ns}}$ & $0,53^{\mathrm{ns}}$ & $0,41^{\mathrm{ns}}$ \\
\hline 50 & $56,21^{\mathrm{ns}}$ & $51,71^{\mathrm{ns}}$ & $41,83^{*}$ & $46,99^{\mathrm{ns}}$ & $0,93^{\mathrm{ns}}$ & $0,44^{\mathrm{ns}}$ & $0,57^{\mathrm{ns}}$ & $0,43^{\mathrm{ns}}$ \\
\hline 100 & $62,31^{\mathrm{ns}}$ & $53,35^{\text {ns }}$ & $44,48^{*}$ & $49,11^{\mathrm{ns}}$ & $1,02^{\mathrm{ns}}$ & $0,33^{\text {ns }}$ & $0,54^{\mathrm{ns}}$ & $0,40^{\mathrm{ns}}$ \\
\hline 150 & $56,34^{\mathrm{ns}}$ & $52,06^{\mathrm{ns}}$ & $51,35^{\mathrm{ns}}$ & $47,02^{\mathrm{ns}}$ & $0,87^{\mathrm{ns}}$ & $0,42^{\text {ns }}$ & $0,52^{\mathrm{ns}}$ & $0,50^{\mathrm{ns}}$ \\
\hline 200 & 55,62 & 47,57 & 48,13 & 46,76 & 0,75 & 0,36 & 0,49 & 0,43 \\
\hline
\end{tabular}

\footnotetext{
ns Não-significativo a 5\% de probabilidade pelo teste Dunnett.
}

* Significativo a 5\% de probabilidade pelo teste Dunnett. 
Tabela 5 - Parâmetros biomecânicos dos fêmures de frangos de corte alimentados com diferentes níveis de balanço eletrolítico

\begin{tabular}{|c|c|c|c|c|c|}
\hline \multirow[t]{2}{*}{ Balanço eletrolítico (mE/kg) } & Fmax $(\mathrm{N})$ & MOR (MPa) & $\mathrm{SpE}(\mathrm{N} / \mathrm{mm})$ & I $\left(\mathrm{m}^{4}\right)$ & Diâmetro $(\mathrm{mm})$ \\
\hline & \multicolumn{5}{|c|}{7 dias } \\
\hline-50 & $22,579^{*}$ & $9,417^{\mathrm{ns}}$ & $11,109^{\mathrm{ns}}$ & $2,90 \mathrm{E}-12^{\mathrm{ns}}$ & $1,401^{\mathrm{ns}}$ \\
\hline 0 & $23,822^{*}$ & $10,901^{\mathrm{ns}}$ & $12,459^{\mathrm{ns}}$ & $2,64 \mathrm{E}-12^{\mathrm{ns}}$ & $1,370^{\mathrm{ns}}$ \\
\hline 50 & $27,174^{*}$ & $11,308^{\mathrm{ns}}$ & $13,510^{\mathrm{ns}}$ & $2,85 \mathrm{E}-12^{\mathrm{ns}}$ & $1,395^{\mathrm{ns}}$ \\
\hline 100 & $24,388^{*}$ & $9,926^{\mathrm{ns}}$ & $10,349^{\mathrm{ns}}$ & $2,81 \mathrm{E}-12^{\mathrm{ns}}$ & $1,362^{\mathrm{ns}}$ \\
\hline 150 & $27,043^{*}$ & $12,178^{\mathrm{ns}}$ & $13,528^{\mathrm{ns}}$ & $2,61 \mathrm{E}-12^{\mathrm{ns}}$ & $1,368^{\mathrm{ns}}$ \\
\hline \multirow[t]{2}{*}{200} & 41,967 & 11,862 & 11,998 & 4,87E-12 & 1,554 \\
\hline & & & 14 dias & & \\
\hline-50 & $91,057^{\mathrm{ns}}$ & $7,688^{\mathrm{ns}}$ & $8,498^{\mathrm{ns}}$ & $3,12 \mathrm{E}-11^{\mathrm{ns}}$ & $2,605^{\mathrm{ns}}$ \\
\hline 0 & $96,042^{\mathrm{ns}}$ & $7,245^{\mathrm{ns}}$ & $10,350^{\mathrm{ns}}$ & $3,80 \mathrm{E}-11^{\mathrm{ns}}$ & $2,723^{\mathrm{ns}}$ \\
\hline 50 & $90,294^{\mathrm{ns}}$ & $6,919^{\mathrm{ns}}$ & $7,878^{\mathrm{ns}}$ & $3,72 \mathrm{E}-11^{\mathrm{ns}}$ & $2,689^{\mathrm{ns}}$ \\
\hline 100 & $99,349^{\mathrm{ns}}$ & $7,160^{\mathrm{ns}}$ & $7,542^{\mathrm{ns}}$ & $3,81 \mathrm{E}-11^{\mathrm{ns}}$ & $2,688^{\mathrm{ns}}$ \\
\hline 150 & $76,254^{\mathrm{ns}}$ & $4,600^{\mathrm{ns}}$ & $4,889^{\mathrm{ns}}$ & $4,73 \mathrm{E}-11^{\mathrm{ns}}$ & $2,882^{\mathrm{ns}}$ \\
\hline \multirow[t]{2}{*}{200} & 117,000 & 8,266 & 8,887 & $3,92 \mathrm{E}-11$ & 2,733 \\
\hline & \multicolumn{5}{|c|}{21 dias } \\
\hline-50 & $193,568^{\mathrm{ns}}$ & $7,206^{\mathrm{ns}}$ & $10,662^{\mathrm{ns}}$ & $1,49 \mathrm{E}-10^{\mathrm{ns}}$ & $3,892^{\mathrm{ns}}$ \\
\hline 0 & $177,937^{\text {ns }}$ & $7,715^{\mathrm{ns}}$ & $9,954^{\mathrm{ns}}$ & $1,23 \mathrm{E}-10^{\mathrm{ns}}$ & $3,704^{\mathrm{ns}}$ \\
\hline 50 & $208,875^{\mathrm{ns}}$ & $9,441^{\mathrm{ns}}$ & $16,132^{*}$ & $1,29 \mathrm{E}-10^{\mathrm{ns}}$ & $3,740^{\mathrm{ns}}$ \\
\hline 100 & $187,257^{\text {ns }}$ & $8,836^{\mathrm{ns}}$ & $10,909^{\mathrm{ns}}$ & $1,07 \mathrm{E}-10^{\mathrm{ns}}$ & $3,587^{\mathrm{ns}}$ \\
\hline 150 & $175,776^{\mathrm{ns}}$ & $7,701^{\mathrm{ns}}$ & $12,230^{\mathrm{ns}}$ & $1,28 \mathrm{E}-10^{\mathrm{ns}}$ & $3,740^{\mathrm{ns}}$ \\
\hline \multirow[t]{2}{*}{200} & 183,954 & 7,928 & 11,773 & $1,18 \mathrm{E}-10$ & 3,628 \\
\hline & \multicolumn{5}{|c|}{42 dias } \\
\hline-50 & $313,495^{\mathrm{ns}}$ & $8,140^{\mathrm{ns}}$ & $13,096^{\mathrm{ns}}$ & $4,93 \mathrm{E}-10^{\mathrm{ns}}$ & $5,326^{\mathrm{ns}}$ \\
\hline 0 & $328,324^{\mathrm{ns}}$ & $7,496^{\mathrm{ns}}$ & $13,004^{\mathrm{ns}}$ & $5,31 \mathrm{E}-10^{\mathrm{ns}}$ & $5,368^{\mathrm{ns}}$ \\
\hline 50 & $277,466^{\mathrm{ns}}$ & $6,600^{\mathrm{ns}}$ & $13,367^{\mathrm{ns}}$ & $5,36 \mathrm{E}-10^{\mathrm{ns}}$ & $5,390^{\mathrm{ns}}$ \\
\hline 100 & $269,137^{\mathrm{ns}}$ & $7,385^{\mathrm{ns}}$ & $12,172^{\mathrm{ns}}$ & $4,61 \mathrm{E}-10^{\mathrm{ns}}$ & $5,201^{\mathrm{ns}}$ \\
\hline 150 & $273,464^{\mathrm{ns}}$ & $6,278^{\mathrm{ns}}$ & $16,790^{\mathrm{ns}}$ & $5,41 \mathrm{E}-10^{\mathrm{ns}}$ & $5,468^{\mathrm{ns}}$ \\
\hline 200 & 249,606 & 5,989 & 13,263 & 4,94E-10 & 5,321 \\
\hline
\end{tabular}

Fmax = força máxima na flexão; MOR = resistência à flexão; $\mathrm{SpE}$ = tenacidade na flexão; $\mathrm{I}$ = momento de inércia.

ns Não-significativo a 5\% de probabilidade pelo teste Dunnett.

* Significativo a $5 \%$ de probabilidade pelo teste Dunnett.

maior incidência de fraturas de fêmures em perus adultos que possuíam menores porcentagens de cálcio. As quantidades relativas e propriedades do mineral, matriz orgânica, determinam suas propriedades em termos de força mecânica. Neste trabalho, aos 7 dias de idade para o balanço eletrolítico de $200 \mathrm{mEq} / \mathrm{kg}$, a força máxima na flexão foi significativamente maior em função das propriedades físicas dos ossos, comprovada pelo aumento do diâmetro ósseo, que implica maior capacidade de suportar força, porém, quando se observaram o MOR e SpE que representam propriedades intrínsecas do material ósseo, excluindo os efeitos dos ajustes geométricos, não foi observada melhora na qualidade do osso. Aos 21 dias para o balanço de $50 \mathrm{mEq} / \mathrm{kg}$, observamos maior valor de SpE. Esta propriedade óssea expressa a capacidade de suportar carga do osso e está relacionada ao colágeno, porém, como não foi observada maior quantidade de proteínas colagenosas para este tratamento, não se pode atribuir o maior valor de $\mathrm{SpE}$ ao percentual desta fração proteica. No entanto, além das quantidades de colágeno, as alterações da orientação das fibras, mesmo sem alterar o grau de maturação, podem contribuir para a manutenção da força óssea, até em casos de diminuição da densidade mineral (Boskey et al., 1999), fator não explorado neste trabalho.

Não houve diferenças significativas $(\mathrm{P}>0,05)$ nos parâmetros físicos diâmetro e inércia em nenhum tratamento em relação ao controle de $200 \mathrm{mEq} / \mathrm{kg}$.

\section{Conclusões}

A idade de 7 dias mostrou-se mais sensível às variações do balanço eletrolítico em níveis inferiores ao controle, pelo menos nas propriedades físicas e químicas como um todo. Portanto, deve-se ter mais cautela ao estabelecer dietas aniônicas para fase inicial, a fim de reduzir problemas de deformações ósseas que possam comprometer a locomoção das aves, prejudicando seu bem-estar e desempenho. Para idades 14, 21 e 42 dias, variações mais amplas dos níveis do balanço eletrolíticos podem ser usadas sem prejuízos para às propriedades ósseas de maneira geral. Isto permite inferir que os níveis ideais de balanço eletrolítico estão na faixa de 150 a $200 \mathrm{mEq} / \mathrm{kg}$. 


\section{Referências}

AMERICAN SOCIETY OF AGRICULTURAL ENGINEERS - ASAE Standard S459. Shear and three-point bending test of animal bone. Saint Joseph: ASAE, 1992. p.581-583.

ARAÚJO, G.M. Variação aniônica e catiônica da dieta sobre as características ósseas de frangos de corte: resistência à quebra, composição mineral e orgânica. 2009. 103f. Dissertação (Mestrado em Ciência Animal) - Universidade Federal de Mato Grosso, Cuiabá.

BARBOSA, A.A.; MORAES, G.H.K.; TORRES, R.A. et al. Avaliação da qualidade óssea mediante parâmetros morfométricos, bioquímicos e biomecânicos em frangos de corte. Revista Brasileira de Zootecnia, v.39, n.4, p.772-778, 2010.

BARREIRO, F.R.; AMARAL, L.A.; SHIMANO, A.C. et al. Physiologic values of broiler femurs at different growth phases using boné densitometry and bone breaking strength. International Journal af Poultry Science, v.10, n.7, p.530-533, 2011.

BERGSTROM, W.; WALLACE, W. Bone as a sodium and potassium reservoir. American Society for clinical investigation, v.33, n.6, p.867-873, 1954.

BOSKEY, A.L.; WRIGHT, T.M.; BLANK, R.D. Collagen and bone strength. Journal of Bone and Mineral Research, v.14, n.3, p.330-335, 1999.

BRADFORD, M. A rapid and sensitive method for the quantitation of microgram quantitaties of protein utilizing the principle of protein-dye binding. Analytical Biochemistry, v.72, n.2, p.248-254, 1976.

BROWN, S.E.; JAFFE, R. Acid-alkiline balance and its effect on bone health. International Journal of Integrative Medicine, v.2, n.6, p.1-12, 2000.

CRESPO, R.; STOVER, S.M.; SHIVAPRASAD, H.L. et al. Microestructure and mineral content of femora in male turkeys with and without fractures. Poultry Science, v.81, p.1184-1190, 2002.

CURREY, J.D. Role of collagen and other organics in the mechanical properties of bone. Osteosporos International, v.14, (Suppl. 5) p.S29-S36, 2003.

FIELD, R.A. Ash and calcium as measures of bone in meat and bone mixtures. Meat Science, v.55, n.3, p.255-264, 2000.

GREEN, J.; KLEEMAN, C. Role of the skeleton in acid-base homeostase. Proceedings of the Nutrition Society, v.61, p.151-164, 2002.

HALLEY, J.T.; NELSON, T.S.; KIRBY, L.K. et al. Effect of altering dietary mineral balance on growth, leg abnormalities, and blood base excess in broiler chicks. Poultry Science, v.66, p.1684-1692, 1986.

HAUSCHKA, P.V.; GALLOP, P.M. Purification and calcium binding properties of osteocalcin, the carboxyglutamate containing protein of bone. In: WASSERMAN, R.H. (Ed.) Calcium binding proteins and calcium function. Amsterdam: Elsevier, 1977. p.338-347.

KARUNAJEEWA, H.; BARR, D.A. Influence of dietary electrolyte balance, source of added potassium and anticoccidial agents on the performance of male broilers. British Poultry Science, v.29, n.1, p.137-147, 1988.

KARUNAJEEWA, H.; BARR, D.A.; FOX, M. Effect of dietary phosphorus concentration and electrolyte balance on the growth performance of broiler chickens. British Poultry Science, v.27, n.4, p.601-612, 1986.

KWAKKEL, R.P.; HOF, G.; ZANDSTRA, T. et al. Diphasic allometric growth of some skeletal bones and the digestive tract in white leghorn pullets consuming ad libitum and restricted diets. Poultry Science, v.77, p.826-833, 1998.

LETERRIER, C.; NYS, Y. Composition, cortical structure and mechanical properties of chicken tibiotarsi: effect of growth rate. British Poultry Science, v.33, n.5, p.925-939, 1992.
MOGHADDAM, H.N.; JANMOHAMMADI, H.; NAJAFABADI, J. The effect of dietary eletrolyte balance on growth, tibia ash and some blood serum electrolytes in young pullets. International Journal of Poultry Science, v.4, n.7, p.493-496, 2005.

MONGIN, P. Role of sodium, potassium and chloride in eggshell quality. In: NUTRITION CONFERENCE OF FLORIDA, Florida, 1980. Proceedings... Florida, 1980. p.114-117.

MONGIN, P. Recent advances in dietary anion-cation balance: applications in poultry. Proceedings of the Nutrition Society, v.40, p.285-294, 1981.

MONGIN, P.; SAUVEUR, B. Interrelationships between mineral nutrition, acid-base, growth and cartilage abnormalities. Proceedings Poultry Science, v.12, p.235-247, 1977.

MONTEIRO, M.P.; MORAES, G.H.K.; FANCHIOTTI, F.E. et al. Alfa-amilase em frangos de corte: efeitos do balanço eletrolítico e do nível protéico da dieta. Revista Brasileira de Zootecnia, v.35, n.3, p.1070-1076, 2006.

MORAES, G.H.K.; RODRIGUES, A.C.P.; SILVA, F.A. et al. Efeito do ácido L-glutâmico e da vitamina $\mathrm{K}$ na composição bioquímica parcial de fêmures de frangos de corte. Revista Brasileira de Zootecnia, v.39, n.4, p.796-800, 2010.

MUAMBA, J.M.M.; GEVERS, D.G. Collagen and non-collagenous proteins in different mineralization stages of human femur. Acta Anatomica, v.134, p.265-268, 1989.

MURAKAMI, A.E. Balanço eletrolítico da dieta e sua influência sobre o desenvolvimento dos ossos de frangos. In: CONFERÊNCIA APINCO DE CIÊNCIA E TECNOLOGIA AVÍCOLA, 2000, Campinas. Anais... Campinas: FACTA, 2000. p.33-61.

OLIVEIRA, A.F.G. Estudo do padrão de crescimento ósseo em frangos de corte de diferentes grupos genéticos criados em duas densidades populacionais. 2006. $73 \mathrm{f}$. Dissertação (Mestrado) - Universidade Estadual de Maringá, Maringá.

OLIVEIRA, M.C.; ARANTES, U.M.; STRINGHINI, J.H. Efeito do balanço eletrolítico da ração sobre parâmetros ósseos e da cama de frango. Revista Biotemas, v.23, n.1, p.203-209, 2010.

OVIEDO-RONDÓN, E.O.; MURAKAMI, A.E.; FURLAN, A.C. et al. Exigências nutricionais de sódio e cloro e estimativa do melhor balanço eletrolítico da ração para frangos de corte na fase préinicial. Revista Brasileira de Zootecnia, v.29, n.4, p.1162-1166, 2000.

PATIENCE, J.F. A review of the role of acid-base balance in amino acid nutrition. Journal of Animal Sciences, v.68, p.398-408, 1990.

REIS, D.T.C.; TORRES, R.A.; BARBOSA, A.A. et al. Efeito de linhagem e sexo nas características geométricas e biomecânicas de tibias de frangos de corte. Acta Scientiarum Animal Sciences, v.33, n.1, p.101-108, 2011.

RIOND, J.L. Animal nutrition and acid-base balance. European Journal of Nutrition. v.40, p.245-254, 2001.

ROSTAGNO, H.S. Tabelas brasileiras para aves e suínosComposição de alimentos e exigências nutricionais. 2.ed. Viçosa, MG: Universidade Federal de Viçosa, 2000. 141p.

SILVA, D.J.; QUEIROZ, A.C. Análises de alimentos: métodos químicos e biológicos. 3.ed. Viçosa, MG: Universidade Federal de Viçosa, 2006. 235p.

SIMONS, P.C.M.; HULAN, H.W.; TEUNIS, G.P. et al. Effect of dietary cation-anion balance on acid-base status and incidence of tibial discondroplasia of broiler chickens. Nutrition Reports International, v.35, n.3, p.591-600, 1987.

SOUZA, B.B.; BERTECHINI, A.G.; TEIXEIRA, A.S. et al. Efeitos dos cloretos de potássio e de amônia sobre o desempenho e deposição de gordura na carcaça de frangos de corte criados no verão. Revista Brasileira de ciência Avícola, v.4, n.3, p.209-218, 2002.

THORP, B.H.; WADDINGTON, D. Relationships between the bone pathologies, ash and mineral content of long bones in 35-day- 
old broiler chickens. Research in Veterinary Science, v.62, n.1, p.67-73, 1997.

VIEITES, F.M.; MORAES, G.H.K.; ALBINO, L.F.T. et al. Balanço eletrolítico e níveis de proteína bruta sobre parâmetros sangüíneos e ósseos de frangos de corte aos 21 dias de idade. Revista Brasileira de Zootecnia, v.33, n.6, p.1520-1530, 2004.
WALDENSTEDT, L. Nutricional factors of importance for optimal leg health in broilers: a review. Animal Feed Science and Technology, v.126, p.291-307, 2006.

WILLIAMS, B.; WADDINGTON, D.; SOLOMON, S. et al. Dietary effects on bone quality and turnover, and $\mathrm{Ca}$ and $\mathrm{P}$ metabolism in chickens. Research in Veterinary Science, v.69, p.81-87, 2000. 